\title{
Nano-oxide Formation by In Situ Oxidation of Copper Thin Films
}

\section{Judith C.Yang, Guangwen Zhou}

Department of Materials Science and Engineering, 848 Benedum Hall, University of Pittsburgh, Pittsburgh, PA 15261.

Oxidation is not only critical for environmental stability but also presents a fascinating opportunity for nano-oxide processing. The ability to form oxide nanostructures of controlled shapes, sizes and distributions have tremendous potential for a wide variety of applications - ranging from novel electronic, magnetic, optical performance to utilization as biological templates. Our goal is the fundamental understanding of the complex kinetics and energetics of oxidation, via in situ ultra-high vacuum transmission electron microscopy (UHV-TEM), that will provide crucial insights in tailoring corrosion resistance or oxide processing at the nanoscale. In our earlier investigations, we discovered that surfaces are key to the initial oxidation processes, where the transport, nucleation and growth of $\mathrm{Cu}_{2} \mathrm{O}$ islands on $\mathrm{Cu}(100)$ were controlled by the surface diffusion of oxygen [1-2]. In the present study, we are systematically investigated the effects of thermodynamic variables, such as temperature and pressure, as well as crystallographic orientation on nano-oxidation mechanisms.

Specifically, single crystal $99.999 \%$ pure $1000 \AA \mathrm{Cu}$ films were grown on (100), (110) and (111) $\mathrm{NaCl}$ in an $\mathrm{UHV}$ e-beam evaporator system. The $\mathrm{Cu}$ film was mounted on a specially prepared $\mathrm{Si}$ mount thatallows for the resistive heating of the specimen. The microscope was a modified JEOL200 CX with a spatial resolution of $2.5 \AA$ and permits introduction of gasses via a leak valve.[3] To remove the native oxide formed due to oxidation the specimen was annealed at $350{ }^{0} \mathrm{C}$ followed by exposure to methanol vapor. $\mathrm{Cu}(100), \mathrm{Cu}(110)$ and $\mathrm{Cu}(111)$ were oxidized by $\mathrm{O}_{2}$ up to $1000^{\circ} \mathrm{C}$ and pressures from $10^{-5}$ torr to 1 atm. For the oxidation conditions examined, $\mathrm{Cu}_{2} \mathrm{O}$ formed epitaxially with respect to the $\mathrm{Cu}$ film.

We find that temperature plays a surprising role in the evolution of the oxide morphology, A medley of oxide nanostructures ranging from pyramids, domes, nanorods to nano-containers are produced by simply varying oxidation temperature (figure 1) [4]. Of particular interest was the unusual quasione-dimensional $\mathrm{Cu}_{2} \mathrm{O}$ nanorod structure. Epitaxial $\mathrm{Cu}_{2} \mathrm{O}$ islands on $\mathrm{Cu}(100)$ surface formed through oxidizing $\mathrm{Cu}(100)$ films at $600^{\circ} \mathrm{C}$ in a UHV-TEM were observed to undergo a shape transition from initially square-in-cross-section islands to elongated islands at a critical size of $\sim 110 \mathrm{~nm}$. Our experimental data on the elongation of $\mathrm{Cu}_{2} \mathrm{O}$ islands agree with the energetic calculations based on the balance between surface and interface energies and the elastic stress relaxation in the three dimensional islands [5]. We developed a kinetic model based on oxygen surface diffusion that fits well with the observed volume evolution of the $\mathrm{Cu}_{2} \mathrm{O}$ islands [6].

We also discovered an unusual nano-container structure at $1000^{\circ} \mathrm{C}$. We propose a new model based on mechanical slip to describe this unusual morphology. The oxide quickly penetrates through the $\mathrm{Cu}$ film due to the high diffusion rates of both copper and oxygen. Then, the $\mathrm{Cu}_{2} \mathrm{O}$ grows laterally, creating a net growth stress normal to the film, where a critical stress is reached and the oxide island slips upward to relieve the growth stress, and then this process repeats itself. This mechanism suggests that the terrace widths of the nano-container should be equal, which was observed. This research is funded by the National Science Foundation (DMR \# 9902863), NACE seed grant, and 
Department of Energy (DEFG02-96ER45439). The experiments were performed at the Materials Research Laboratory, UIUC. The authors thank Ray Twesten, Kevin Colrary for their help.

\section{Reference}

[1]. J.C. Yang, M. Yeadon, B. Kolasa and J.M. Gibson, Appl. Phys. Lett., 70, 26 (1997)

[2]. J.C. Yang, M. Yeadon, B. Kolasa and J.M. Gibson, Scripta Materalia, 38, 8 (1998)

[3]. M.L. McDonald, J.M. Gibson and F.C. Underwald, Rev. Sci. Instrum. 60, 700 (1989)

[4]. G.W. Zhou, J.C. Yang, Appl. Surf. Sci. in press (2003)

[5]. J. Tersoff, R. Tromp, Phys. Rev. Lett. 70, 2782 (1993)

[6]. G.W. Zhou, J. C. Yang, Phys. Rev. Lett. 89, 6101(2002)
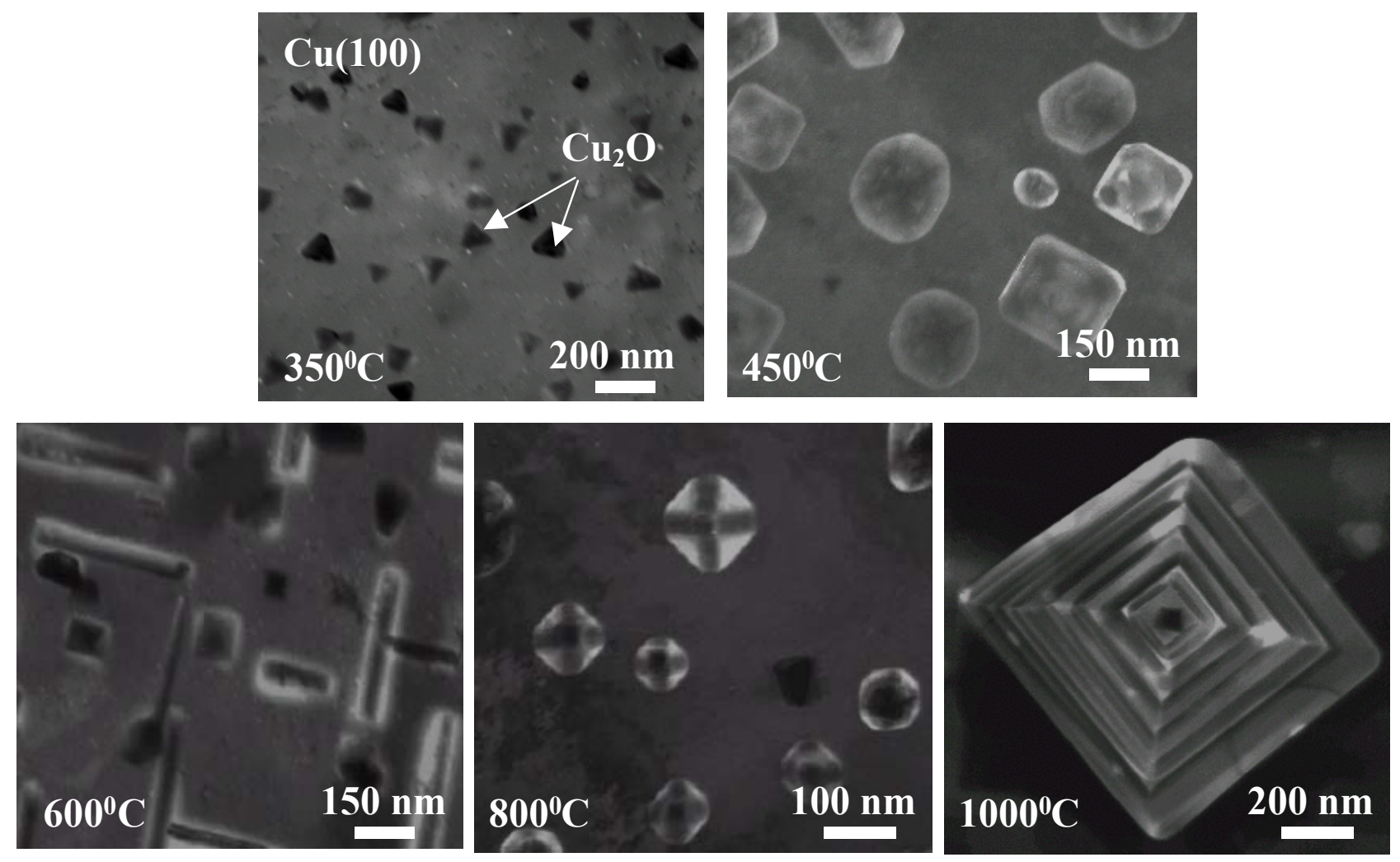

Figure 1: Bright field images of the $\mathrm{Cu}(100)$ films during oxidation at $\mathrm{P}\left(\mathrm{O}_{2}\right)=5 \times 10^{-4}$ Torr at various temperatures ranging from $350^{\circ} \mathrm{C}$ to $1000^{\circ} \mathrm{C}$, where an assortment of epitaxial $\mathrm{Cu}_{2} \mathrm{O}$ island morphologies are observed. 